\title{
Validation of the Spanish version of the children's self-perceptions of adequacy in and predilection for physical activity (CSAPPA) questionnaire
}

\author{
Juan Antonio Moreno-Murcia ${ }^{1 *}, M^{a}$ Celestina Martínez-Galindo ${ }^{1}$, Luis Miguel Ruiz Pérez ${ }^{2}$, \\ Virginia García Coll ${ }^{2}$ and José Martín-Albo ${ }^{3}$ \\ ${ }^{1}$ Universidad de Miguel Hernández de Elche ${ }^{2}$ Universidad de Castilla-La Mancha \\ ${ }^{3}$ Universidad de Zaragoza
}

(Received September 8, 2011; Accepted October 17, 2011)

\begin{abstract}
The main purpose of the present study was to evaluate the validity of the Spanish version of the Children's Self-Perceptions of Adequacy in and Predilection for Physical Activity questionnaire (Hay, 1992). Two studies were carried out with independent samples $(N=688 / N=201)$. The first study checked the internal consistency, the factorial and the predictive validity of the scale in relation to gender, and the second, checked the criterion validity of the questionnaire in relation to exercise rate and intensity. The design was a crosssectional with self-reported questionnaires. The results revealed a structure of three oblique factors and 12 interactions among residual errors with adequate internal consistency. The MANOVA showed significant differences in relation to gender, but the effect sizes were low or moderate. The analysis of invariance in relation to the school of origin of the participants revealed that factor structure was invariant. On the other hand, the analysis of structural equations in the second study revealed that practice predicted the perception of adequacy in physical activity, this adequacy predicted the perception of predilection for physical activity, and this situation predicted enjoyment, too. In conclusion, this study provided support for the reliability and validity of the Spanish version of the CSAPPA) questionnaire.
\end{abstract}

Key words: self-perception, factorial analysis, adequacy, predilection, enjoyment, physical activity.

Validación española del cuestionario de autopercepción sobre la adecuación y predilección de la actividad física (CSAPPA)

RESUMEN: El objetivo de este estudio fue validar el Cuestionario de Autopercepción sobre la Adecuación y Predilección de la Actividad Física de Hay (1992) al contexto español. Para ello se llevaron a cabo dos estudios con muestras independientes $(N=688$ y $N=201)$. El primer estudio analizó los indicios de consistencia interna, la validez factorial y predictiva de la escala en función del sexo, mientras la segunda trató de analizar la validez de criterio del cuestionario en relación a la tasa de ejercicio y la intensidad del mismo. El diseño fue transversal con el empleo de un cuestionario de autoinforme. Los resultados del primer estudio mostraron una estructura factorial de tres factores oblicuos y 12 interaciones 
entre los residuales con una consistencia interna adecuada. El MANOVA mostró diferencias significativas en función del sexo aunque los tamaños de los efectos fueron bajos o moderados. Un análisis de invarianza en función del centro de procedencia de los participantes (rural versus urbana) mostró que la estructura factorial era invariante. Por otra parte, el análisis de ecuaciones estructurales en el segundo estudio mostró que la práctica física predijo positivamente la percepción de adecuación de la actividad física, esta predijo positivamente la percepción de predilección hacia la actividad física y esta situación predijo también positivamente el disfrute en la práctica. En conclusión, este estudio ofrece datos sobre la validez y fiabilidad de la versión española del cuestionario CSAPPA.

Palabras clave: autopercepción, análisis factorial, adecuación, predilección, diversión, actividad física.

Self-concept has long been considered a reliable indicator of psychological health and a mediator of behaviour. Consequently it has been seen as a desirable characteristic in adolescents to promote their success in terms of academic performance (Gold, 1982), social conduct (Markus \& Wurf, 1987), healthy behaviour (Pastor, Balaguer \& García Merita, 2000) and their satisfaction with life (Balaguer, 2002). However, adolescence is a key period for the formation of one's self-concept. Dramatic changes take place during this period and important cognitive changes have an effect on the development of the "self" (Coleman \& Hendry, 1999; Harter, 1999). This is why it is so important to study this period.

Physical self-concept has been defined as a multidimensional mental representation which people have regarding their corporal reality, including not only bodily elements, but also other perceptive, cognitive, affective and emotional features (Cash \& Pruzinsky, 1990). Fox and Corbin (1989) specifically identified four physical self-perceptions: physical condition, sports competence, body attractiveness and physical strength. A number of studies (Crocker, Eklund \& Kowalsky, 2000; Hagger, Ashford \& Stambulova, 1998; Moreno \& Cervelló, 2005; Raudsepp, Liblik \& Hannus, 2002) have linked these physical self-perceptions to sports practice among adolescents in reciprocal correlations: adolescents doing sports on a regular basis tended to have a better perception of their sports competence and, conversely, those perceiving themselves as more competent tended to do sports to a greater extent.

The notion of self-concept has frequently been mistaken for other concepts used to account for phenomena associated with self-referential thinking. One of these concepts is self-efficacy. Self-efficacy is defined as a person's opinion of his or her ability to successfully perform "specific" tasks or activities. Selfefficacy may vary in relation to the activity, the level of difficulty of the task or the circumstances involved (Bandura, 1986). Consequently, self-concept and self-efficacy are not interchangeable. Self-concept focuses on a global view, whereas self-efficacy concentrates on the personal appreciation of one's own ability to successfully cope with a given task or not.

For a better understanding of the self-referential thinking that leads people 
to adopt a particular attitude to the practice of sports, our study concentrated on self-concept. Hay (1992) maintains that there are two key self-perceptions involved in the personal assessment of one's own performance level: the perception of adequacy and the perception of predilection. The first one refers to the perception of one's own capability to achieve a goal and the second to the child's intentionality in choosing a given physical activity. To study these self-perceptions Hay (1992) designed a scale based on hisher Children's Self-Perceptions of Adequacy in and Predilection for Physical Activity (CSAPPA) questionnaire (Cairney et al., 2005; Cairney et al., 2008; Hay \& Shepard, 1998; Hay \& Caerney, 2006). The analysis of the factor structure of the scale revealed the existence of three factors as compared to the two hypothesized: adequacy ( 7 items), predilection (9 items) and enjoyment (3 items). Results showed that the scale had excellent internal consistency (.90 for adequacy; .91 for predilection; .89 for enjoyment), a factor structure with three oblique factors and adequate construct validity and predictive validity.

For a better understanding of self-referential thinking and with the purpose of using self-perceptions in more accurate theoretical models, it was important to confirm and validate these records with different populations and cultures. For this reason we carried out two studies with independent samples. The first study aimed at a preliminary validation with a sample of adolescent Spanish students in order to see if the scale showed signs of reliability and factorial validity. The second study aimed at checking whether the scale provided evidence of predictive validity and a prediction model for enjoyment during the practice of sports was put to the test. By means of an analysis of structural equations, we tested the impact of physical-sport activity on the self-perception of adequacy, the possible impact of this perception on predilection for physical activity, and, finally, the effect of this predilection on the self-perception of enjoyment.

\section{STAGE 1: PRELIMINARY VALIDATION OF THE SPANISH VERSION OF THE CSAPPA}

This study aimed at a preliminary validation of Hay's (1992) Children's SelfPerceptions of Adequacy in and Predilection for Physical Activity questionnaire in the Spanish context of physical education.

\section{METHOD}

\section{Participants}

A total of 688 Spanish students, 359 male and 329 female, took part in this study. Their average age was 12.12 years $(S D=1.42)$. Four hundred and ten students came from schools located in a rural environment and 278 came from schools in an urban environment. 


\section{Instrument}

Children's Self-Perceptions of Adequacy in and Predilection for Physical Activity questionnaire (Hay, 1992). The questionnaire evaluates three dimensions: adequacy, predilection and enjoyment. The scale had 20 items (7 for adequacy, 10 for predilection and 3 for enjoyment) in response to the question What is the most like you?, on a Likert-type scale, with options ranging from (1) Not true for me to (4) Completely true for me.

\section{Procedure}

Since Hay's questionnaire had previously been used in Spain only as part of a doctoral thesis (Mata, 2008) without further validation among a Spanish population, we deemed it necessary to correctly validate and adapt it to the Spanish educational context. For this purpose we implemented the back-translation technique suggested by Hambleton (1996). Thus, the items were first translated into Spanish and then a group of translators back-translated them into English to see if the final text coincided with the original version. Items were later submitted to three experts in the field for evaluation (Lynn, 1986). The experts were asked to assess how relevant the items were to measure the constructs targeted and the correctness of the wording. Subsequently, a small group of students were provided with the full battery of questions to verify that these were correctly understood and to make any necessary changes. Finally, with the permission of the head teachers of the schools and the parents or legal guardians of underage participants, the administration schedule was drawn up.

In order to clarify any questions about the correct meaning not only of the questionnaire items but also of the instructions given at the beginning, the questionnaires were completed in the presence of the principal researcher. Questionnaires were completed in about 10 minutes.

\section{Data analysis}

Firstly, an initial analysis of the psychometric profile of the scale was made. The internal consistency was first checked by means of Cronbach's alpha and subsequently a confirmatory factor analysis was carried out to see if the threefactor structure, with the corresponding items, was suitable for the Spanish environment.

\section{RESULTS}

\section{Descriptive analysis}

The statistical descriptors (mean, standard deviation, skewness and kurtosis) of the items used in our study are shown in Table 1. As can be seen, all skewness 
absolute values were under 2 and kurtosis absolute values were under 7, which bears a resemblance to a normal curve, as Curran, West and Finch (1996) recommend. Likewise, Mardia's coefficient was 98.90, which deviates from multivariate normality. With these results we used Maximum Likelihood Estimation with bootstrapping (Byrne, 2001).

Table 1. Statistical Descriptors of CSAPPA Items

\begin{tabular}{|lcccc|}
\hline & $M$ & $S D$ & Skewness & Kurtosis \\
\hline 1. Cuando terminan las clases estoy deseando salir a jugar (PRE) & 2.58 & 1.16 & -.07 & -1.44 \\
2. Me divierto mucho en las clases de educación física (DIS) & 3.49 & .78 & -1.62 & 2.19 \\
3. Me gustan los juegos en los que hay que moverse o correr (PRE) & 3.12 & 1.02 & -.86 & -.51 \\
4. Me divierto haciendo deporte (PRE) & 3.44 & .85 & -1.47 & 1.32 \\
5. Pienso que la clase de educación física es la mejor de todas (DIS) & 3.26 & .90 & -1.12 & .41 \\
6. Soy bueno/a en los juegos en los que hay que moverse o correr (ADE) & 3.21 & .87 & -.97 & .26 \\
7. Me gustan los deportes (PRE) & 3.37 & .86 & -1.24 & .69 \\
8. Me hago daño siempre que practico algún deporte (PRE) & 2.91 & .91 & -.43 & -.65 \\
9. Me gusta salir a practicar juegos en los que hay que moverse o correr (PRE) & 2.94 & 1.07 & -.66 & -.84 \\
10. Se me da bien la mayoría de los deportes (ADE) & 2.97 & 1.00 & -.66 & -.66 \\
11. Aprendo fácilmente los juegos en los que hay que moverse o correr (ADE) & 3.40 & .82 & -1.36 & 1.27 \\
12. Creo que soy de los/as mejores en los deportes (ADE) & 2.55 & 1.99 & -.14 & -1.03 \\
13. Los juegos que practico en educación física son difíciles (ADE) & 3.22 & .89 & -.94 & .03 \\
14. Prefiero ver jugar a mis compañeros/as (PRE) & 3.50 & .84 & -1.70 & 1.96 \\
15. Soy de los/as últimos/as en ser elegido/a para jugar (ADE) & 2.75 & 1.08 & -.35 & -1.15 \\
16. Me gusta tomarme con calma los recreos (PRE) & 2.58 & 1.22 & -.05 & -1.58 \\
17. Me lo paso bien en las clases de educación física (DIS) & 3.56 & .77 & -1.89 & 3.04 \\
18. Soy suficientemente bueno/a en los deportes de equipo (ADE) & 2.95 & .99 & -.52 &.- .84 \\
19. Me gustan los juegos tranquilos (PRE) & 3.08 & 1.04 & -.75 & -.71 \\
20. Me gusta salir a jugar los fines de semana a juegos en los que hay que & 2.81 & 1.12 & -.44 & -1.19 \\
moverse o correr (PRE) & & & & \\
\hline
\end{tabular}

Note. Items evaluating adequacy have the letters (ADE), predilection (PRE) and enjoyment (ENJ). 


\section{Confirmatory factor analysis}

The CSAPPA factor structure was evaluated with a confirmatory factor analysis (CFA) by means of the AMOS v. 6.0 program. For the data analysis we used as entries a Maximum Likelihood Estimation with bootstrapping (500 resamplings) and the covariance matrix between items. A 3-factor oblique model was analysed. Each factor corresponds to each of the three dimensions. The fit of the model was assessed with a combination of absolute and relative fit indexes which included: $i$. the IFI, which is very consistent and indicates improvements in the fit of the model by degrees of freedom, as compared with the baseline of the independent model, as Hoyle (1995) recommends; $i i$. the CFI, because it is easier to interpret than other indexes and indicates reductions in poor fits; iii. the SRMR index, for which values of .06 or below indicate an outstanding fit and values of .08 or below indicate a good fit (Hu \& Bentler, 1999); $i v$. the RMSEA index, which provides a measurement of discrepancy by degrees of liberty and, according to Jöreskog \& Sörbom (1993), indicates that the model based on the sample used represents the population with values of .05 or below (values under .08 are interpreted as an acceptable fit too).

CFA results revealed a poor fit of the model in general $(\mathrm{TLI}=.80 ; \mathrm{IFI}=.81$, $\mathrm{CFI}=.81$, RMSEA $=.07$ and SRMR $=.06$ ). Consequently, we went on to test a new model considering 12 interactions between residual errors as suggested by the modification indexes. The fit of the new model was acceptable $(\mathrm{TLI}=.90$; $\mathrm{IFI}=.90, \mathrm{CFI}=.90, \mathrm{RMSEA}=.05$ and $\mathrm{SRMR}=.05$ ). The standardized values of factor weights ranged from .13 to .74 and all parameter estimations were significant $(p<.05)$. As can be seen in Table 2, covariances between items were positive and in particular higher between predilection and adequacy items. As far as covariances are concerned, records for both latent and residual factors were positive and significant (Table 3). Bootstrapping revealed that the differences between the average values of parameters in the resamplings and the sample records were low and the bias-corrected intervals indicated that the hypothesis that parameters values were equal to null could be discarded. Finally, mention must be made of the fact that the recorded correlations between the predilection and the adequacy factors were positive, strong and significant $(r=.83, p<.05)$. The enjoyment factor also revealed positive correlations with the predilection and enjoyment factors ( $r=.59$ and .67 respectively, $p<.05$ ). 


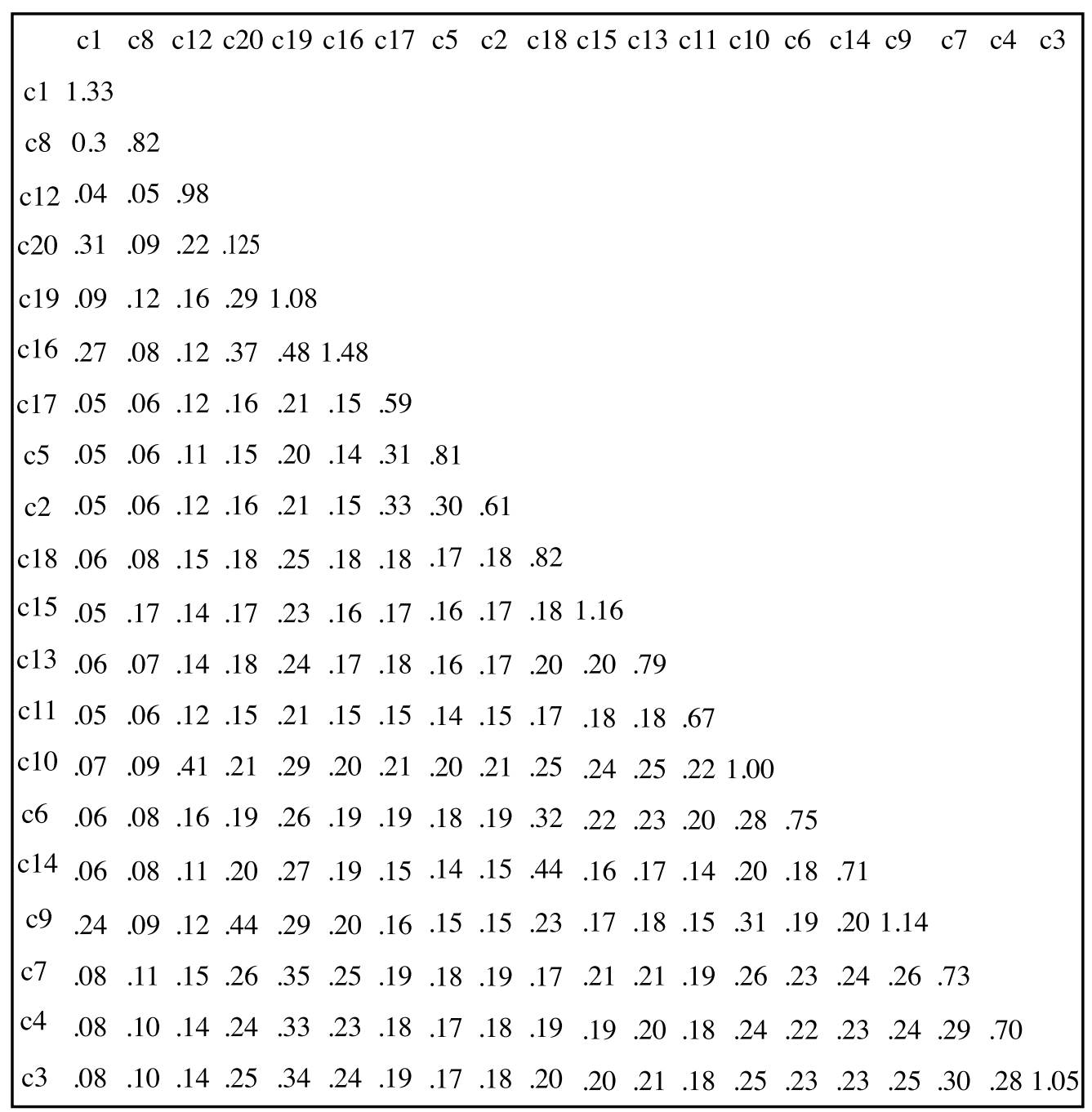


Table 3. Covariances of Latent Variables and Residual Errors

\begin{tabular}{|llcl}
\hline & & Estimation & S.E. \\
Predilection & $<-->$ Enjoyment & .185 & .022 \\
Predilection & $<-->$ Adequacy & .228 & .026 \\
Adequacy & $<-->$ Enjoyment & .190 & .021 \\
e15 & $<-->$ e18 & .238 & .037 \\
e20 & $<-->$ e1 & .246 & .046 \\
e10 & $<-->$ e12 & .241 & .034 \\
e9 & $<-->$ e20 & .227 & .040 \\
e16 & $<-->$ e19 & .205 & .040 \\
e16 & $<-->$ e20 & .161 & .043 \\
e16 & $<-->$ e1 & .208 & .049 \\
e9 & $<-->$ e1 & .171 & .043 \\
e20 & $<-->$ e12 & .095 & .034 \\
e9 & $<-->$ e10 & .096 & .030 \\
e15 & $<$ e8 & .101 & .033 \\
\hline
\end{tabular}

Note. All parameters were significant $(p<.05)$

\section{Analysis of invariance}

The analysis of invariance was made in relation to the environment of origin, since this variable is relevant to the study (Ruiz et al., 2005). The analysis aimed at determining whether or not the structure of the confirmatory factor analysis is invariant in two independent samples, one of students from schools located in rural environments $(n=410)$ and the other of students from schools located in urban environments $(n=278)$. For that purpose we put four models to the test in a multigroup analysis by means of the AMOS v. 6.0 program. Model 1 
corresponds to a restriction-free model. Model 2 takes the factor weights of the measuring model as invariant values. Model 3 is an invariant model as far as covariances are concerned. Finally, model 4 represents an invariant model as far as residual errors are concerned. Results revealed that the four models had acceptable fit indexes. The differences found between the restriction-free model (Model $1)$ and all the other models were not significant $(p>.05)$, a fact, which strongly supports the idea that the model proposed, is invariant with regard to students' rural/urban provenance (Byrne, Shavelson \& Muthén, 1989; Marsh, 1993).

\section{Analysis of internal consistency}

The internal consistency values recorded with Cronbach's alpha were .70 for adequacy, .72 for predilection and .72 for enjoyment.

\section{Differences by gender}

In order to determine any possible differences by gender we carried out a multivariate analysis of variance (MANOVA). This revealed a significant effect of gender on the three subscales $(F(3,688)=16.77, p<.05)$, with moderate effect size $\left(\mathrm{n}^{2}=.07\right)$. The univariate analysis showed that the three dimensions presented significant differences in relation to gender: $F(1,688)=48.14$ for predilection, $F(1,688)=24.78$ for adequacy and $F(1,688)=7.58$ for enjoyment. For each of them the effect size ranged from moderate to small values $\left(\eta^{2}=.07\right.$, $\eta^{2}=.03$ and $\eta^{2}=.01$, respectively).

\section{DISCUSSION}

The first study aimed at an analysis of the factor structure, the invariance with regard to students' provenance, the internal consistency and the differences in relation to gender with the purpose of obtaining psychometric data for the CSAPPA. Results tend to partially support the factorial validity and the scale internal consistency and predictive validity. Note must be taken of method effects seemingly induced by different perturbation factors affecting the factors of predilection and adequacy. In this respect, the method effects could be induced by several variables, such as age and reading ability, as Marsh (1996) and Corwyn (2000) suggest, or by the formulation itself of the items (some of them negative statements, others positive statements), a fact which would presumably have an impact only on the factors of adequacy and predilection by easily biasing the response, regardless of the actual meaning (Carmines \& Zeller, 1979). In addition, the strong correlation between predilection and adequacy, confirming Hay's (1992) findings, could suggest certain levels of predictive relationship not only with these factors but also with the enjoyment ascribed to the activity. Consequently, whereas the items concerning the dimensions of predilection and adequacy indicate predisposition or motivation towards an activity (e. g., When 
school finishes I look forward to going out and doing sports), the items concerning the enjoyment dimension refer to an experiential judgment (e. g., I really enjoy physical education classes). On the other hand, the performance of physical exercise probably tends to increase the perception of adequacy in that exercise as a result of a competence gain in the performance, which, in turn, increases the perception of the predilection for that exercise. This question is dealt with in the following study.

\section{STAGE 2: CRITERION VALIDITY AND MODEL INVARIANCE ANALY- SIS OF THE CSAPPA IN RELATION TO GENDER}

Hay (1992) was one of the pioneers in suggesting the hypothesis that the self-perceptions governing our behaviour were probably related to our practice of physical sports. According to Hay, the failure to see oneself as capable of successfully performing a task can discourage any sign of inclination towards a given physical activity and a subsequent increase in the inactivity rate finally resulting in a lower probability of acquiring healthy habits with age.

On the other hand, the enjoyment factor can probably be considered as a consequence of the predilection for a type of physical activity, and this predilection as a consequence of the adequacy of the participant's resources to perform that activity. According to the flow model (Jackson, 1996), the balance between skill and challenge provokes motivation towards the activity and the perception of enjoyment in its practice. This could be related to the occurrence of method effects in our first study dealing with the dimensions of predilection and adequacy. These two dimensions are probably affected by elements such as the participant's performance level and the demands of the task (e. g., physical, technical requirements, etc.) as perceived by the participant in connection with the physical activity in his/her mind when filling in the questionnaire. Thus, the enjoyment of the activity, probably determined by the relationship between these two dimensions (predilection and adequacy), would also be related to the occurrence of a flow experience during the performance of the physical exercise. By determining any possible impact of physical-sport activity on the self-perception of adequacy, of adequacy on the predilection for physical activity, and of predilection, in turn, on the self-perception of enjoyment, our second study aims at providing supporting evidence for the criterion validity. For that purpose we implemented an analysis of structural equations. Given the gender-related differences recorded in Study 1, we also checked the model invariance in relation to gender.

\section{METHOD}

\section{Participants}

The sample consisted of 201 students (102 male and 99 female), with a mean age of 13.92 years and a standard deviation of 1.33 . 


\section{Instruments}

Physical-sport activity. In order to measure the latent variable, physical-sport activity, we used two observable variables: rate of physical exercise and degree of intensity of exercise. To record the exercise rate, participants were asked how many days per week they did physical exercise and for how long (in minutes). The participant's exercise rate was defined as the number of minutes per week that he or she did exercise. On the other hand, to determine the degree of intensity of the physical exercise involved we used a question taken from the Health Behaviour in School-aged Children (HBSC) Questionnaire by Wold (1989): In your free time, how many times a week do you usually exercise so hard that you get out of breath or sweat? This question had 7 possible answers: 1 (never), 2 (less than once a week), 3 (once a month), 4 (once a week), 5 (2-3 times a week), 6 (4-6 times a week) and 7 (every day).

Children's Self-Perceptions of Adequacy in and Predilection for Physical Activity Questionnaire (CSAPPA; Hay, 1992). We used the scale already described in Study 1. For a better identification of the model by means of at least two indicators, we split each of the factors, adequacy and predilection, into two indicators. For the latent factor of adequacy, these indicators were the respective average values of a group of four and, alternatively, three items. For the predilection factor, the indicators were the respective average of a group of five items in each case. For the latent variable of enjoyment, we used the three items concerned. Internal consistency by means of Cronbach's alpha was .79 for adequacy, .79 for predilection and .77 for enjoyment.

\section{Procedure}

The procedure was similar to the one already seen in Study 1.

\section{Data analysis}

We firstly calculated the statistical descriptors of the variables involved. Subsequently, we used a structural equations model (SEM) to study the relationships between the variables. In a two-step approach, as recommended by Anderson and Gerbing (1998), we firstly generated a measuring model, a strategy which can provide tools with construct validity and corresponds with a confirmatory factor analysis. Secondly, we generated a structural model to analyse the correlations between physical-sport activity, self-perception of predilection and the adequacy in and the enjoyment of the activity. The model arrangement presents one exogenous variable (physical-sport activity) and three endogenous variables (adequacy self-perception, predilection for physical activity and self-perception of enjoyment of physical activity). 


\section{RESULTS}

\section{Descriptive analysis}

As can be seen in Table 4, kurtosis and skewness values for the variables under study are near to null. Both curves present univariate normality according to the suggestion made by Curran, West \& Finch (1996). Likewise, Mardia's coefficient is 10.39 , which reveals a slight deviation from multivariate normality. For that reason we used a Maximum Likelihood Estimation with bootstrapping (500 resamplings).

Table 4. Statistical Descriptors for the Variables of the Structural Model

\begin{tabular}{|lcccc|}
\hline & $M$ & $S D$ & Skewness & Kurtosis \\
\hline Exercise rate & 18.61 & 19.89 & 1.09 & 1.81 \\
Intensity & 3.84 & 1.99 & -1.18 & -1.29 \\
Adequacy 1 & 2.95 & .67 & -.32 & -.16 \\
Predilection 1 & 2.90 & .59 & -.27 & -.61 \\
Predilection 2 & 2.58 & .80 & .11 & -.32 \\
Enjoyment 1 & 2.89 & 1.04 & .40 & -.81 \\
Enjoyment 2 & 2.50 & 1.15 & -.02 & -1.11 \\
Enjoyment 3 & 2.74 & 1.04 & -.21 & -1.19 \\
\hline Multivariate & & & & 10.39 \\
\hline
\end{tabular}

\section{Measuring model}

The measuring model with the correlations between each latent variable and its indicators was tested by means of a confirmatory factor analysis. The model was identified, since each latent variable had at least two indicators (McDonald and Ho, 2002). A combination of absolute and relative fit indexes was used. The results of the measuring model showed good fit indexes $(\mathrm{CFI}=.99$; IFI $=.99$; 
$\mathrm{TLI}=.99, \mathrm{GFI}=.97, \mathrm{RMSA}=.04 ; \mathrm{SRMR}=.03)$. Likewise, all factor parameters proved to be significant $(p<.05)$.

\section{Structural model}

The structural equations model under evaluation hypothesized that the physical-sport activity has an effect on the adequacy self-perception for physical exercise, the adequacy self-perception on the predilection self-perception, and the predilection self-perception on the enjoyment self-perception. The model was recursive and identified, since there was no correlation between the errors in the endogenous variables. Consequently, it complied with the orthogonality rule proposed by McDonald (1997). The results of the hypothesized model showed a good fit $(\mathrm{CFI}=.99 ; \mathrm{IFI}=.99 ; \mathrm{TLI}=.98 ; \mathrm{GFI}=.96 ; \mathrm{RMSA}=.05 ; \mathrm{SRMR}=.04)$ and all correlations were significant. On this occasion standardized regression weights ranged from .59 to .89 . The bootstrapping revealed that the difference between the average values of parameters in the 500 resamplings and the records of our sample were low, and the bias-corrected intervals clearly dismissed the hypothesis that the values of parameters were equal to null. Figure 1 shows that physical-sport activity positively predicts self-perception of adequacy in physical exercise, that adequacy self-perception positively predicts predilection perception and, finally, that predilection perception predicts enjoyment. These three factors are accounted for with variance values of 35\%, 63\% and $77 \%$ respectively. Table 5 shows the covariances between all the variables concerned. As can be seen, all covariances are positive and there is a high correlation between the measurements recorded for each construct. 


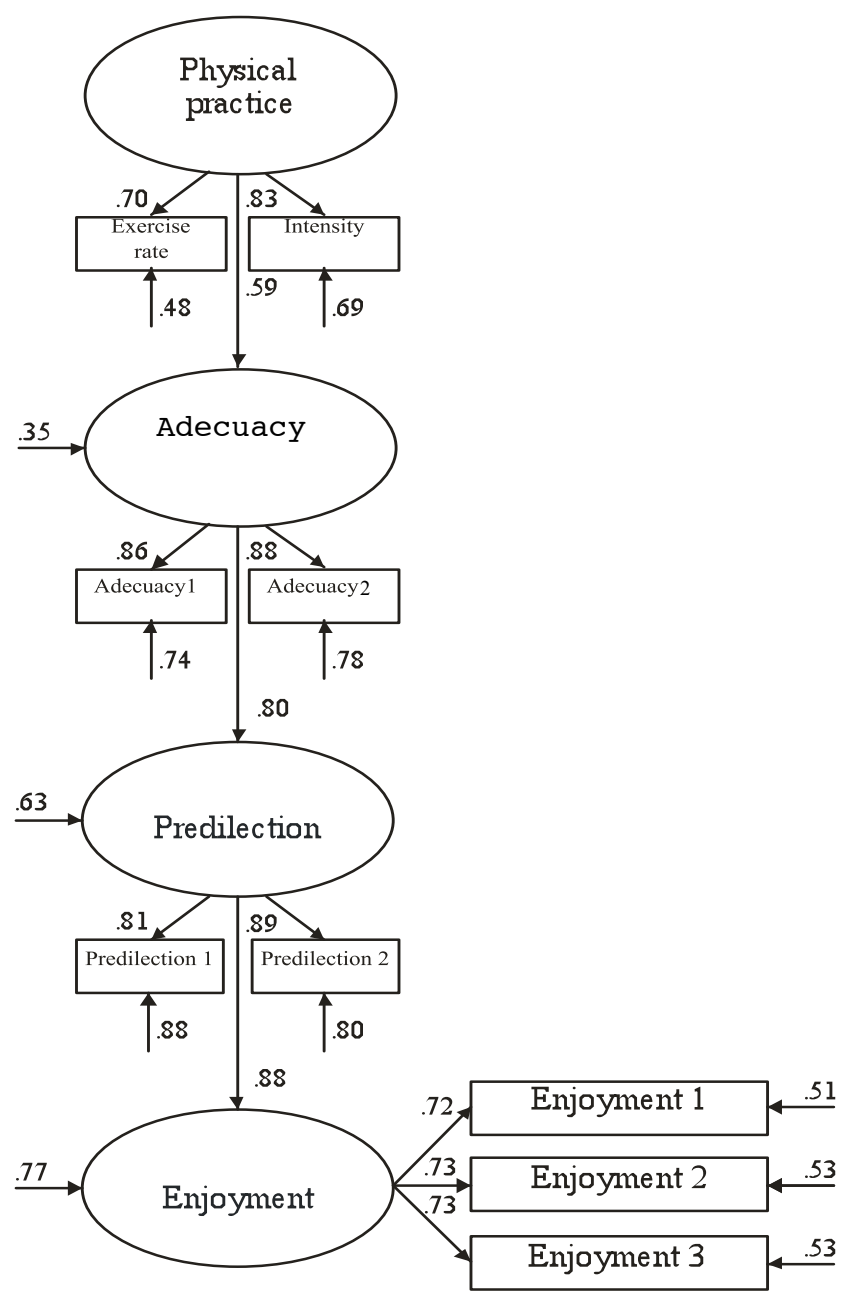

Figure 1. Structural equations model (all parameters are standardized and are statistically significant. Variances are shown above the little arrows). 
Table 5. Covariances of the Variables and Standardized Residual Covariances

\begin{tabular}{|lccccccccc|}
\hline & 1 & 2 & 3 & 4 & 5 & 6 & 7 & 8 & 9 \\
\hline Predilection 1 & .34 & .12 & -.24 & -.06 & -.21 & .12 & -.35 & .13 & -.09 \\
Predilection 2 & .34 & .63 & -.35 & -.06 & .24 & -.20 & -.05 & .32 & -.09 \\
Enjoyment 1 & .31 & .47 & 1.09 & .19 & -.09 & .77 & .88 & 2.10 & 2.84 \\
Enjoyment 2 & .35 & .52 & .63 & 1.31 & -.09 & -.12 & .03 & .53 & .71 \\
Enjoyment 3 & .32 & .47 & .57 & .63 & 1.08 & -.03 & .34 & -.19 & -.85 \\
Adequacy 1 & .22 & .33 & .30 & .34 & .31 & .45 & .02 & -.23 & .28 \\
Adequacy 2 & .25 & .38 & .35 & .39 & .36 & .39 & .58 & .02 & -.21 \\
Intensity & .37 & .55 & .51 & .57 & .52 & .56 & .65 & 3.93 & .00 \\
Exercise rate & 3.08 & 4.63 & 4.27 & 4.78 & 4.33 & 4.75 & 5.49 & 22.67 & 393.57 \\
\hline
\end{tabular}

Note. Covariances are on the diagonal and lower part of the diagonal; standardized residual covariances are on the diagonal.

\section{Analysis of invariance}

The analysis of invariance was implemented in relation to gender. For that purpose we carried out a multigroup analysis by means of the AMOS v. 6.0 programme. A total of six models were tested. Model 1 corresponds to a restrictionfree model. Model 2 takes the factor weights of the measuring model as invariant values. Model 3 is an invariant model as far as structural weights are concerned. Model 4 takes the structural covariances as being invariant. Model 5 represents an invariant model as far as the structural errors are concerned. Finally, Model 6 takes the residual errors as being invariant. As can be seen in Table 6, results revealed that all models presented acceptable fit indexes and the differences found between the restriction-free model (Model 1) and all the others were not significant $(p>.05)$, a fact which strongly supports the idea that the model proposed is invariant with regard to gender (Byrne, Shavelson \& Muthén,1989; Marsh, 1993). 
Table 6. Fit Indexes for The Models Tested in a Comparative Multigroup Analysis in Relation to Gender

\begin{tabular}{|lcccccccc|}
\hline & $d f$ & $\chi^{2}$ & $p$ & IFI & CFI & TLI & RMSEA & SRMR \\
\hline Model 1 & 48 & 52.90 & .29 & .99 & .99 & .99 & .04 & .04 \\
Model 2 & 53 & 58.35 & .28 & .99 & .99 & .99 & .04 & .04 \\
Model 3 & 56 & 59.26 & .36 & .99 & .99 & .99 & .04 & .04 \\
Model 4 & 57 & 60.91 & .34 & .99 & .99 & .99 & .04 & .04 \\
Model 5 & 60 & 63.53 & .35 & .99 & .99 & .99 & .04 & .04 \\
Model 6 & 69 & 71.53 & .39 & .99 & .99 & .99 & .04 & .04 \\
\hline
\end{tabular}

\section{DISCUSSION}

This study aimed at providing evidence of the suitability of the psychometric profile of the Spanish version of the Children's Self-Perceptions of Adequacy in and Predilection for Physical Activity questionnaire designed by Hay (1992). For that purpose we carried out two studies with independent samples. The results of the first study partially supported the factorial validity and internal consistency of the scale together with its predictive validity in relation to gender. Results also confirmed a strong correlation between predilection for, adequacy in and enjoyment of the activity, just as Hay (1992) had found. This fact led us to consider a possible predictive correlation not only between these two self-perceptions (adequacy and predilection) but also of either of the two with enjoyment. These predictive correlations were confirmed by the second study: the analysis of structural equations proved that the performance of physical exercise increases the perception of the adequacy in the exercise, as a result of the gain in competence. The process reinforces the perception of predilection for a particular activity, a perception, which, in turn, reinforces the perception of enjoyment while taking part in the activity.

Our results are in line with the records provided by Crocker, Eklund \& Kowalsky (2000), Hay \& Caerney (2006), Hagger, Ashford \& Stambulova (1998) and Moreno \& Cervelló (2005) concerning the correlations between physical self-perceptions and sports practice among adolescents: adolescents who practice sports on a regular basis tend to improve their perception of their own sports competence. If someone feels competent, he or she will also feel capable of successfully achieving his or her goals in the activity concerned, i. e., will perceive himself/herself as adequately prepared to carry out that physical activity. 
Our data can be also interpreted as supporting the theoretical guidelines which are the basis of the theory of self-efficacy (Bandura, 1986). According to this theory, everybody has a series of opinions about his or her own capabilities to successfully perform "specific" tasks or activities. Those opinions may vary according to the activity, the level of difficulty involved or the circumstances of the case. The theory predicts that if the person feels he/she can do the activity, he/she will exhibit stronger predilection and proclivity for choosing those physical activities which he/she thinks he/she will be more successful in. Thus, when taking part in a willingly chosen activity also assessed as potentially successful, the person will experience a positive emotional state in the form of pleasure, happiness and fun, which is the definition of enjoyment suggested by Scanlan and Symons (1992).

In the last decades a series of studies have confirmed that enjoyment is a key motive in encouraging people to perform physical-sport activities (Castillo \& Balaguer, 2001; Ebbeck, Gibbsons \& Loken-Dahle, 1995). The multidirectional correlations hypothesized in this kind of analyses have been sufficiently confirmed.

However, the analysis of structural equations is also bound to a series of limitations which must be taken into account and dealt with in future research. Firstly, despite providing a predictive model for a more comprehensive and better understanding of possible correlations between the variables that presumably have an impact (in our case, on the perception of adequacy, predilection and enjoyment), this kind of correlational studies cannot provide cause-effect correlations. Secondly, as Hershberger (2006) explains, the technique of structural equations poses the problem of multiple equivalent models and, the hypothesized model in our study must inevitably be interpreted as one among many other possible models. As already mentioned in our preliminary discussion in connection with the interaction problems involved in the scale, future studies should deal more extensively with these method effects and carry out comparative analyses implementing CTCU, CTUM and CTCM models.

In conclusion, in our study the CSAPPA questionnaire has proved to be a useful and reliable tool to measure perceptions of subjects' adequacy in, predilection for and enjoyment of a physical activity in a Spanish school context. However, further research is needed either to confirm or refute the results obtained for other populations and with different statistical analyses. A true validation requires much more than one single study. Future approaches will inevitably have to carry out longitudinal studies and experimental designs to test the impact of sports practice on people's self-perceptions and of these perceptions on particular motivational states (enjoyment, general behaviour, life styles, drug consumption, etc.) Likewise, researchers should also investigate in depth the causes underlying the acquisition of particular attitudes about one's own capability to perform different activities according to the gender of the subject. 


\section{REFERENCES}

Anderson, J. C., \& Gerbing, D. W. (1998) Structural equation modelling in practice: A review and recommended two-step approach. Psychological Bulletin, $103,411-423$.

Balaguer, I. (2002). Estilos de vida en la adolescencia. Valencia: Promolibro.

Bandura, A. (1986). Social foundations of thought and action: A social cognitive theory. Englewood. Cliffs, NJ: Prentice-Hall.

Byrne, B. M. (2001). Structural equation modeling with Amos: Basic concepts, applications, and programming. Mahwah, NJ: Erlbaum.

Byrne, B. M., Shavelson, R. J., \& Muthén, B. (1989). Testing for the equivalence of factor covariance and means structures: the issue of partial measurement invariance. Psychological Bulletin, 105, 456-466.

Cairney, J., Hay, J.M Faught, B., Mandingo, J., \& Flouris, A. (2005). Developmental coordination disorder, self.efficacy toward physical activity, and play: Does the gender matter? Adapted Physical Activity Quarterly, 22, (1), 67-82

Cairney, J., Hay, J., Faught, B.E., Léger, L., \& Mathers, B. (2008). Generalized selféfficacy and performance on the 20 metre shuttle run in children. American Journal of Human Biology, 20,(2), 132-138.

Carmines, E. G., \& Zeller, R. A. (1979). Reliability and validity assessment. Beverly Hills, CA: Sage.

Cash, T. F., \& Pruzinsky, T. (1990). Body images: Development, deviance and change. New York: Guilford Press.

Castillo, I., \& Balaguer, I. (2001). Dimensiones de los motivos de práctica deportiva de los adolescentes valencianos escolarizados. Apunts: Educación Física y Deportes, 63, 22-29.

Coleman, J. C., \& Hendry L. B. (1999). The nature of Adolescence. London: Routledge.

Corwyn, R. F. (2000). The factor structure of global self-esteem among adolescents and adults. Journal of Research in Personality, 34, 357-379

Crocker, P. R. E., Eklund, R. C., \& Kowalsky, K. C. (2000). Children's physical activity and physical self-perceptions. Journal of Sports Sciences, 18, 383394.

Curran, P. J., West, S. G., \& Finch, J. F. (1996). The robustness of test statistics to non-normality and specification error in confirmatory factor analysis. Psychological Methods, 1 (1), 16-29.

Ebbeck, V., Gibbons, S. L., \& Loken-Dahle, L. J. (1995). Reasons for adult participation in physical activity: an interactional approach. International Journal of Sport Psychology, 26, 262-275.

Fox, K. R., \& Corbin, C. B. (1989). The Physical Self-Perception Profile: Development and preliminary validation. Journal of Sport and Exercise Psychology, 11, 408-433.

Gold, M. (1982). Scholastic experiences, Self-Esteem, and Delinquent behavior: A theory for alternative schools. En M. Rosenberg and H. B. Kaplan (Eds.), 
Social psychology of the self-concept (pp. 440-451) Illinois: Harlan Davidson, Inc.

Hagger, M., Ashford, B., \& Stambulova, N. (1998). Russian and British children's physical self-perceptions and physical activity participation. Pediatric Exercise Science, 10, 137-152.

Hambleton, R. K. (1996). Adaptación de tests para su uso en diferentes idiomas y culturas: fuentes de error, posibles soluciones y directrices prácticas. En J. Muñiz (Ed.), Psicometría (pp. 207-238). Madrid: Universitas.

Harter, S. (1999). The construction of the self. A developmental perspective. New York: The Guilford Press.

Hay, J. A. (1992). Adequacy in and predilection for physical activity in children. Clinical Journal of Sport Medicine, 2, 192-201.

Hay, J., \& Shepard, R. (1998). Perceptions and patterns of physical activity: A comparison of Mohawk/Cayuga and non native adolescents. American Journal of Human Biology, 10, (5), 629-635

Hay, J., \& Caerney, J. (2006). Development of the habitual activity estimation scale for clinical research: A systematic approach. Pediatric Exercise Science, $18,(2), 193-202$

Hershberger, S. L. (2006). The problem of equivalent structural models. En G. R. Hancock, y R. O. Mueller (Eds.), Structutral equation modeling: a second course (pp. 13-42). Greenwich, CT: Information Age Publishing.

Hoyle, R. H. (1995). Structural equation modelling: Concepts, issues, and applications. Thousand Oaks, CA: Sage.

Hu, L., \& Bentler, P. M. (1999). Cut-off criteria for fit indexes in covariance structure analysis: Conventional criteria versus new alternatives. Structural Equation Modeling, 6, 1-55.

Jackson, S. A. (1996). Toward a conceptual understanding of the flow experience in elite athletes. Research Quarterly for Exercise and Sport, 67, 76-90.

Jöreskog, K. G., \& Sörbom, D. (1993). Structural equation modeling with the SIMPLIS command language. Chicago: Scientific Software International.

Lynn, M. (1986). Determination and quantification of content validity. Nursing Research, 35, 382-385.

Markus, H., \& Wurf, E. (1987). The dynamic self-concept: A social psychological perspective. Annual Review of Psychology, 38, 299-337.

Marsh, H. W. (1993). The multidimensional structure of physical fitness: invariance over gender and age. Research Quartely for Exercise and Sport, 64, 256-273.

Marsh, H. W. (1996). Positive and negative self-esteem: A substantively meaningful distinction or artifactors? Journal of Personality and Social Psychology, 70, 810-819.

Mata, E. (2008). Problemas evolutivos de coordinación motriz y competencia fisica percibida en educación fisica. Unplished Doctoral Dissertation. Toledo: Universidad de Castilla La Mancha.

McDonald, R. P. (1997). Haldane's lungs: A case study in path analysis. Multi- 
variate Behavioral Research, 32, 1-38.

McDonald, R. P., \& Ho, M. H. R. (2002). Principles and practice in reporting statistical equation analyses. Psychological Methods, 7 (1), 64-82.

Moreno, J. A., \& Cervelló, E. (2005). Physical self-perception in Spanish adolescents: effects of gender and involvement in physical activity. Journal of Human Movement Studies, 48, 291-311.

Pastor, Y., Balaguer, I., \& García-Merita, M. L (2000). Influence of multidimensional self-concept on health related lifestyle. International Journal of Psychology, 35 (3/4), 169.

Raudsepp, L., Liblik, R., \& Hannus, A. (2002). Children's and adolescents' physical self-perceptions as related to moderate to vigorous physical activity and physical fitness. Pediatric Exercise Science, 14 (1), 97-106.

Ruiz, R., Bermejo, F., Cano, A., Pérez, J. L., Piris, G., Sánchez, S., Grajal, L., \& Romero, B. (2005). Resistencia en niños de $4^{o}$ primaria. Revista Internacional de Medicina y Ciencias de la Actividad Física y el Deporte, 19, (Retrieved from http://www. cdeporte.rediris.es/revista/revista23/artpieplano.pdf).

Scanlan, T. K., \& Simons, J. P. (1992). The construct of sport enjoyment. En G. C. Roberts (Ed.), Motivation in sport and exercise (pp. 199-215). Champaign, IL: Human Kinetics.

Wold, B. (1989). Lifestyles and Physical Activity. Doctoral Thesis: University of Bergen. 